\title{
Perancangan Sistem Informasi Selam Program Studi Ekowisata Bawah Laut Politeknik Negeri Manado
}

\author{
MexU. Pesika*, Yonathan Parassab \\ aProgram Studi Ekowisata Bawah Laut, Jurusan Pariwisata, Politeknik Negeri Manado , \\ bProgram Studi Teknik Informastika Jurusan Teknik Elektro Politeknik Negeri Manado
}

KATA KUN C I

Perancangan

Sistem informasi
Selam

\begin{abstract}
A B S T R A K
Ekowisata Wisata Bawah Laut adalah salah satu program studi di Politeknik Negeri Manado yang salah satu tujuannya adalah untuk mendukung dunia pariwisata di Indonesia Khususnya di Provinsi Sulawesi Utara. Pengolahan Data selam pada Program Studi Ekowisata Bawah Laut selama ini dilakukan dengan cara mencatat di buku. Menyelam dimana, perangkat yang digunakan, waktu penyelaman dan hal lain yang menyangkut penyelaman dilakukan dengan cara mencatat. Kebutuhan akan pengolahan data peyelaman berbasis komputer dirasakan sangat mendesak. Selain untuk kebutuhan perekaman data, memproses dan dalam melaporkan kegiatan perkuliahan. Tujuan perancangan sistem informasi selam Program Studi Ekowisata Bawah Laut adalah merancang dan membuat sistem pengolahan data penyelaman berbasis komputer sehingga pengolahan data penyelaman yang selama ini dilakukan dengan cara mencatat di buku akan dilakukan dengan menggunakan aplikasi baik untuk merekam, memproses data dan menghasilkan informasi. Metode yang digunakan untuk membangun sistem menggunakan metode waterfall, dimulai dengan tahapan penetapan kebutuhan sistem, desain, implementasi dan pengujian unit, integrasi dan pengujian sistem kemudian tahapan operasi dan perawatan. Hasil dari penelitian ini adalah Perangkat Lunak Sistem informasi selam pada program studi ekowisata bawah laut Politeknik Negeri Manado.

A B S T R A C T

Underwater Tourism Ecotourism is one of the study programs in the Manado State Polytechnic which one supports to support the world of tourism in Indonesia, especially in North Sulawesi Province. Diving Data Processing in the Underwater Ecotourism Study Program so far has been done by recovering in books. Diving where, equipment used, time diving and other things that save diving is done by recovering. The need for computer-based dive data processing was received very satisfactorily. In addition to the purposes of data recording, processing and reporting of lecture activities. The purpose of designing an information system for the Underwater Ecotourism Study Program is to organize and create a computer-based diving data processing system for data processing diving which has been done by updating books to be carried out using good applications to assist, process data and produce information. The method used to build the system using the waterfall method, starting with the stages of determining the system requirements, design, implementation and unit testing, integration and testing of the system begins the operation and maintenance stages. The results of this study are Dive Information System Software in the underwater ecotourism study program Manado State Polytechnic.
\end{abstract}

\begin{tabular}{l} 
K E Y W O R D S \\
\hline Design \\
Information System \\
Dive
\end{tabular}

TERSEDIA ONLINE

31 Oktober 2019

\author{
Pendahuluan \\ Program Studi Ekowisata Bawah Laut adalah salah \\ satu Program Studi pada Jurusan Pariwisata Politeknik
}

Negeri Manado. Sesuai dengan nama program studinya, salah satu kompetensi yang wajib dimiliki mahasiswa yang menempuh pendidikan pada program studi bawah laut adalah kompetensi selam. Program

\footnotetext{
*Corresponding author: Jurusan Teknik Elektro Politeknik Negeri Manado, Alamat Jl. Politeknik, Kel. Buha, Manado

Email address: yonatan.pa@gmail.com

Published by FMIPA UNSRAT (2019)
} 
Studi Ekowisata bawah Laut dipersiapkan untuk mendukung wisata bawah laut di Indonesia khususnya di Sulawesi Utara yang memiliki pesona bawah laut yang sedang berkembang saat ini adalah Taman Nasional Laut (TNL) Bunaken [1].

Selama ini proses pengolahan data penyelaman masih menggunakan sistem manual, sehingga dalam pencatatan masih dilakukan berbasis kertas yang kemudian dipindahkan ke komputer dengan menggunakan program aplikasi perkantoran umum untuk menghasilkan informasi apabila ada kebutuhan informasi mengenai penyelaman. Hal ini mengakibatkan adanya kebutuhan waktu yang cukup lama apabila ada kebutuhan informasi. Pengolahan data dengan mencatat membutuhkkan waktu yang lama untuk pencarian data [2].

Data maupun informasi mengenai penyelaman merupakan kebutuhan yang sangat penting, mengingat dalam aktivitas penyelaman terdapat resiko yang bisa dikatakan tinggi, baik resiko terhadap penyelam dalam hal ini mahasiswa dan dosen, maupun resiko terhadap lingkungan. Diharapkan dengan adanya sistem informasi manajemen penyelaman dapat meminimalisir resiko penyelaman dan meningkatkan mutu penyelenggaraan pendidikan dan perkuliahan di Program studi ekowisata bawah laut Politeknik Negeri Manado.

Artikel ini membahas mengenai bagaimana membangun sistem informasi selam pada Program Studi Ekowisata Bawah Laut Politeknik Negeri Manado. Tujuan penelitian ini adalah untuk merancang dan membangun aplikasi perangkat lunak yang didesain untuk membantu pengolahan data selam pada Program Studi Ekowisata Bawah Laut Politeknik Negeri Manado, dimana selama ini data selam dikelola dengan cara konvensional yaitu dengan cara mencatat dibuku selam. Hasil Penelitian ini aplikasi perangkat lunak yang dapat menerima input data selam, memproses dan menghasilkan informasi mengenai aktivitas selam baik mahasiswa maupun dosen pada Program Studi Ekowisata Bawah Laut Politeknik Negeri Manado.

\section{Material dan Metode}

Penelitian ini menggunakan beberapa metode, yaitu Pengumpulan data baik data primer dan sekunder menggunakan beberapa metode, yaitu observasi, wawancara dan dokumentasi [3]. Metode Pengembangan sistem waterfall adalah metode yang digunakan untuk pengembangan sistem informasi selam Program Studi Ekowisata Bawah Laut [4]. Terdiri dari 5 tahapan, yatitu definisi kebutuhan sistem, desain sistem dan perangkat lunak, implementasi dan pengujian unit, Integrasi dan pengujian sistem, operasi dan perawatan.

Tahapan Desain sistem menggunakan beberapa perangkat, yaitu flow chart, entity relationship diagram, dan context diagram yang telah teruji dan banyak digunakan sebagai perangkat untuk mendesain sistem [5].

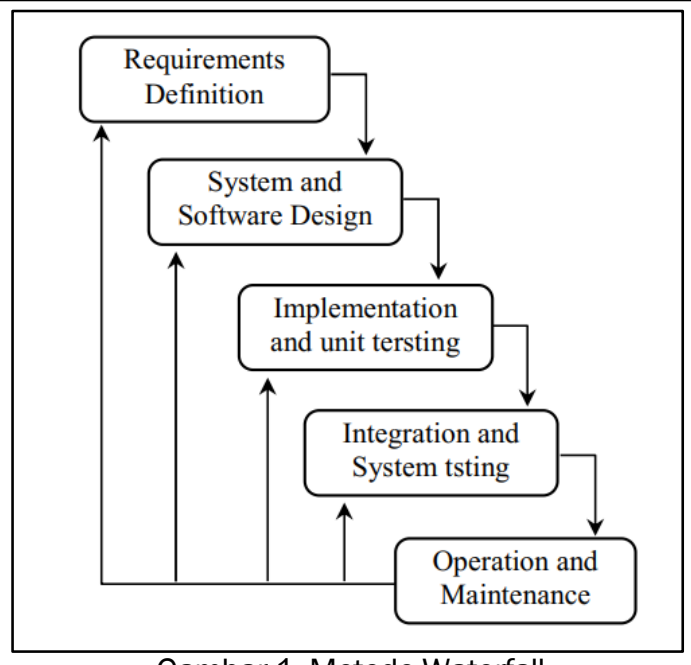

Gambar 1. Metode Waterfall.

\section{Hasil dan Pembahasan}

\section{Requirements Definition}

Definisi kebutuhan sistem ditetapkan berdasarkan kebutuhan pengguna dan pengambilan data pada Program Studi Ekowisata Bawah Laut Politeknik Negeri Manado, yaitu merancang dan menghasilkan aplikasi sistem informasi selam yang berfungsi sebagai pengolah data berbasis komputer.

\section{System and Sotfware Design}

Perancangan sistem menggunakan beberapa perangkat, yaitu :

\section{Diagram konteks}

Perangkat desain Diagram Konteks digunakan untuk merancang aliran data dan informasi yang berasal dari entitas, diproses oleh sistem informasi dan menghasilkan informasi yang dibutuhkan oleh entitas. Diagram konteks menggambarkan sistem secara umum.

Gambar berikut adalah diagram konteks Sistem Informasi Selam Program Studi Ekowisata Bawah Laut Politeknik Negeri Manado.

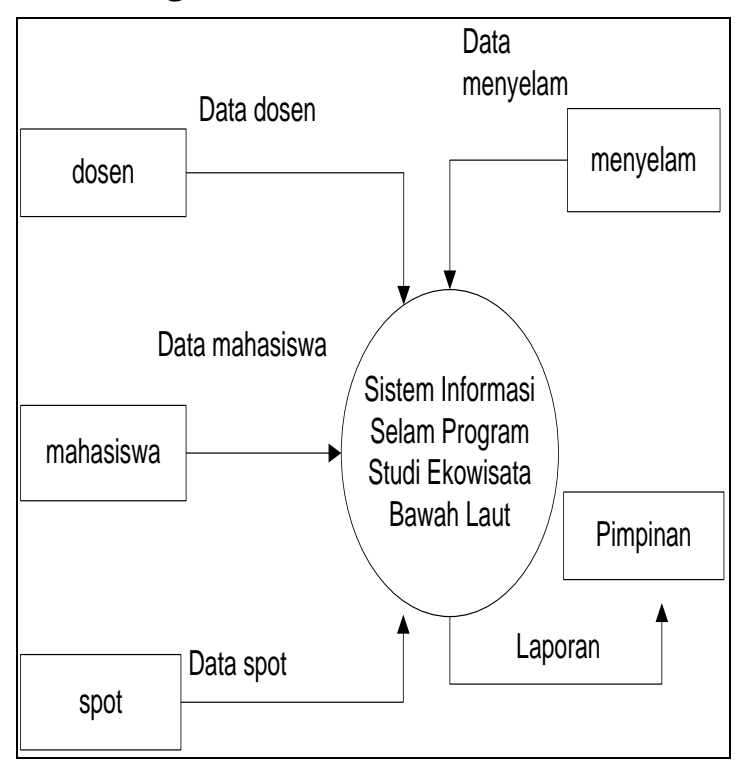

Gambar 2. Diagram Konteks sistem informasi selam 
Entity Relationalship diagram (ERD)

Perangkat desain ERD digunakan untuk mendesain basis data pada sistem informasi selam.

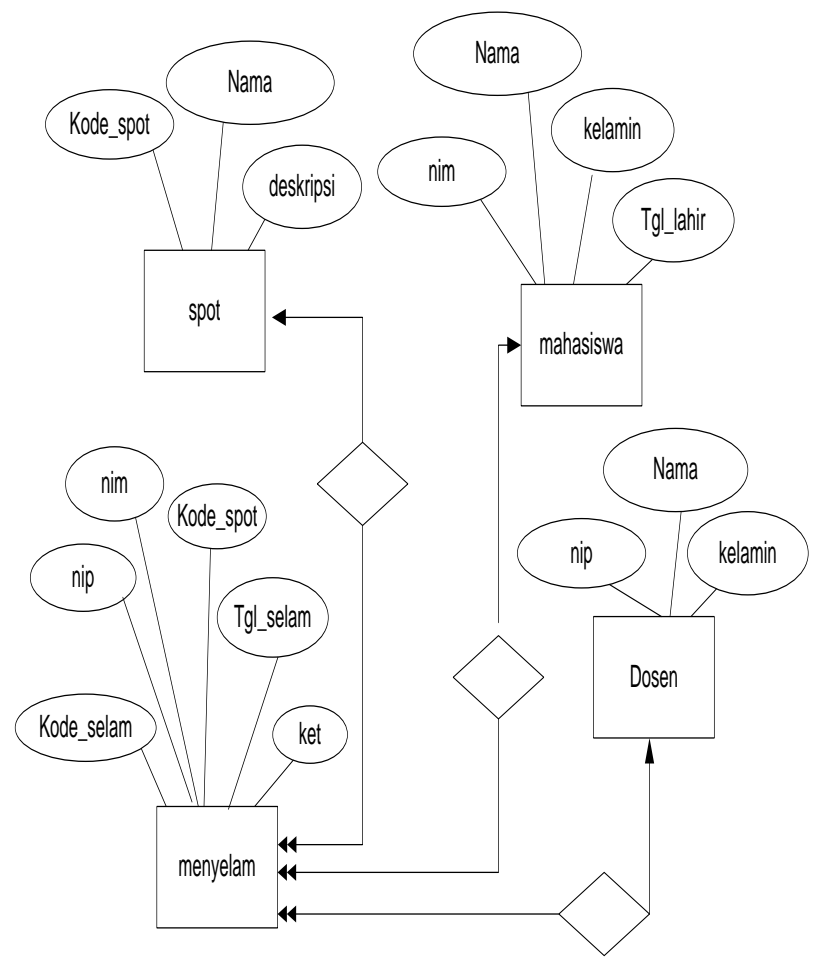

Gambar 3. ERD Sistem

\section{Implementation and unit testing}

Sistem informasi selam terdiri dari beberapa unit, diantaranya :

Unit Pengolahan data Dosen

Berikut adalah gambar unit pengolahan data dosen yang digunakan untuk mengolah data dosen pada sistem informasi selam

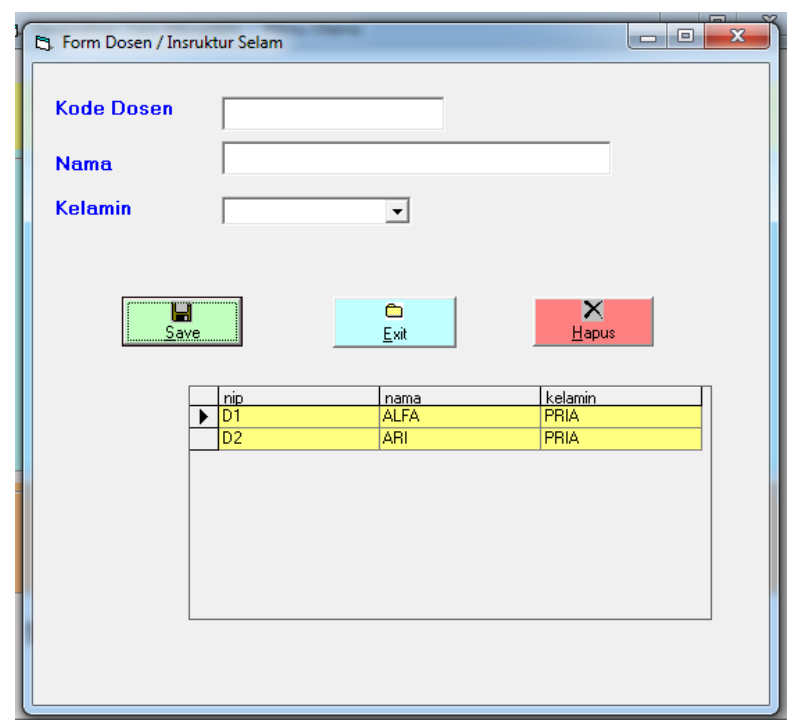

Gambar 4. Unit pengolahan data Dosen

\section{Unit pengolahan data mahasiswa}

Berikut adalah gambar unit pengolahan data mahasiswa yang digunakan untuk mengolah data mahasiswa pada sistem informasi selam

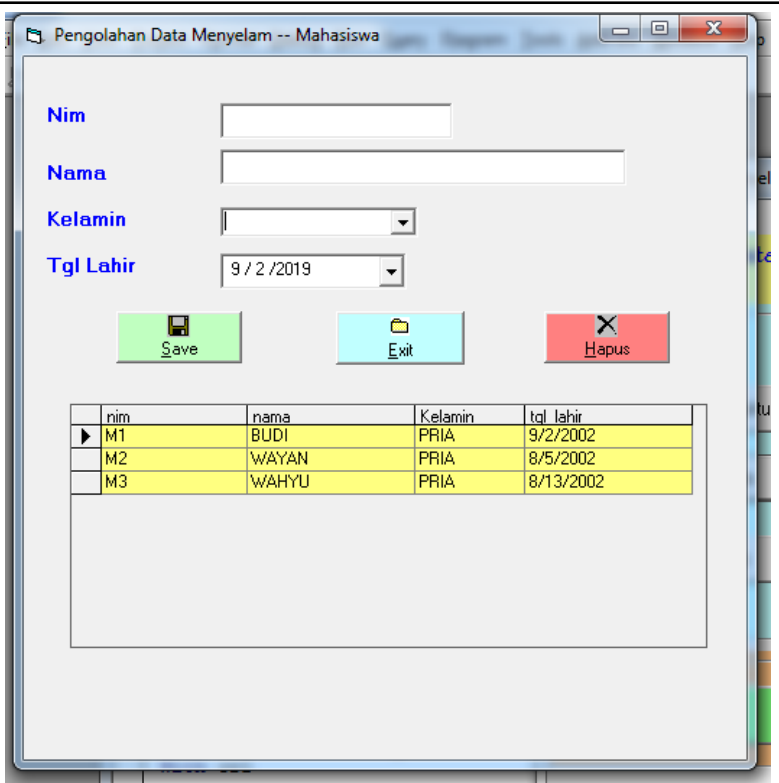

Gambar 5. Unit pengolahan data mahasiswa

Unit sistem pada tahapan ini dibuat dan diuji untuk memastikan telah berjalan dengan benar sesuai dengan kebutuhan sistem.

\section{Integration and system testing}

Tahapan ini adalah tahapan dimana dilakukan integrasi seluruh unit dan melakukan pengujian.

Berikut adalah gambar Menu Utama Sistem Informasi Selam

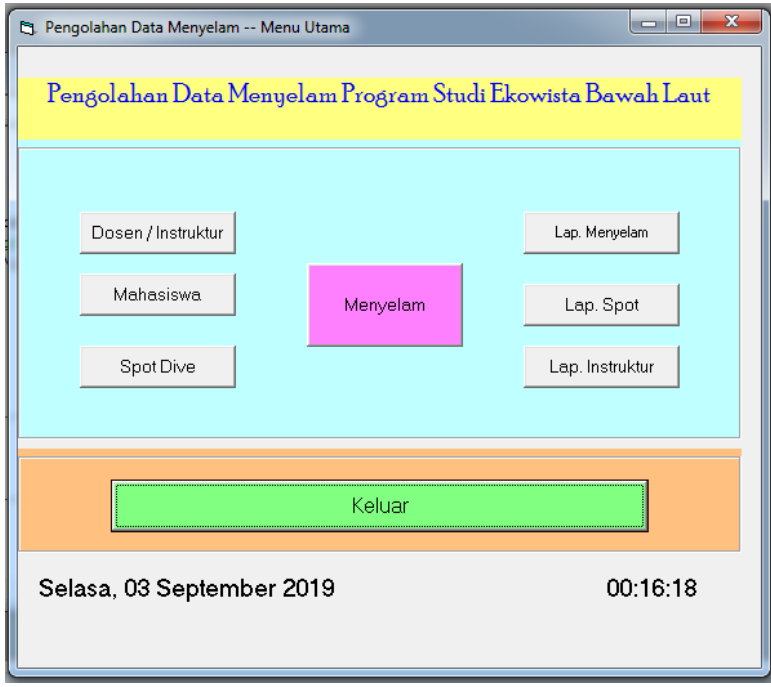

Gambar 6. Menu Utama

\section{Operation and Maintenance}

Tahapan operation dan maintenance adalah tahapan dimana sistem digunakan dan dirawat guna memastikan bahwa sistem informasi selam pada Program Studi Politeknik Negeri Manado berjalan dengan benar sesuai dengan kebutuhan sistem.

\section{Kesimpulan}

Berdasarkan penelitian yang dilakukan pada Program Studi Ekowisata Bawah Laut, kebutuhan pengolahan data selam berbasis aplikasi komputer dibutuhkan untuk mengolah dan menghasilkan 
informasi yang cepat dan akurat dibandingkan mengolah data selam yang dilakukan selama ini dengan mencatat pada buku.

\section{Ucapan Terimakasih}

Tim Peneliti mengucapkan terimakasih kepada Politeknik Negeri Manado yang telah mendanai penelitian ini. Penulis juga menghaturkan terimakasih kepada semua pihak yang terkait dengan penelitian ini

\section{Daftar Pustaka}

Bagindo, M. P., Sanim, B., \& Saptono, T. (2016). Model Bisnis Ekowisata di Taman Nasional Laut Bunaken dengan Pendekatan Business Model Canvas. MANAJEMEN IKM: Jurnal Manajemen Pengembangan Industri Kecil Menengah, 11(1), 80-88.

Saraswati, E. (2013). Sistem Informasi Akademik Berbasis Web Pada Sekolah Menengah Pertama Negeri 3 Pringkuku. IJNS-Indonesian Journal on Networking and Security, 2(4).

Gunawan, I. 2013. Metode penelitian kualitatif. Jakarta: Bumi Aksara.

Sommerville, lan. 2011. "Software Engineering (Rekayasa Perangkat Lunak)." Erlangga, Jakarta

Parassa, yonatan. 2017. Analysis of Tourist Information System Model in North Sulawesi Province. International Journal of computer applications (IJCA), 175 : 11-16. 